\title{
Work hours, weight status, and weight-related behaviors: a study of metro transit workers
}

\author{
Kamisha H Escoto ${ }^{1 *}$, Simone A French², Lisa J Harnack², Traci L Toomey ${ }^{2}$, Peter J Hannan², Nathan R Mitchell ${ }^{2}$
}

\begin{abstract}
Background: Associations between hours worked per week and Body Mass Index (BMI), food intake, physical activity, and perceptions of eating healthy at work were examined in a sample of transit workers.

Methods: Survey data were collected from 1086 transit workers. Participants reported hours worked per week, food choices, leisure-time physical activity and perceptions of the work environment with regard to healthy eating. Height and weight were measured for each participant. Multivariate linear and logistic regressions were conducted to examine associations between work hours and behavioral variables. Associations were examined in the full sample and stratified by gender.

Results: Transit workers working in the highest work hour categories had higher BMI and poorer dietary habits, with results differing by gender. Working 50 or more hours per week was associated with higher BMI among men but not women. Additionally, working 50 or more hours per week was significantly associated with higher frequency of accessing cold beverage, cold food, and snack vending machines among men. Working 40 or more hours per week was associated with higher frequency of accessing cold food vending machines among women. Reported frequency of fruit and vegetable intake was highest among women working 50 or more hours per week. Intake of sweets, sugar sweetened beverages, and fast food did not vary with work hours in men or women. Physical activity and perception of ease of eating healthy at work were not associated with work hours in men or women.

Conclusions: Long work hours were associated with more frequent use of garage vending machines and higher BMI in transit workers, with associations found primarily among men. Long work hours may increase dependence upon food availability at the worksite, which highlights the importance of availability of healthy food choices.
\end{abstract}

\section{Background}

Obesity rates are high among employed adults, have shown consistent increase over the past few decades and vary by occupational group [1]. Most adults spend 8 to 12 hours a day at work, which likely affects other domains in their lives such as self-care behavior and physical health $[2,3]$. It is therefore important to determine the aspects of employment that influence body weight and weight-related behaviors. The exact mechanisms that underlie the relationship between work and obesity are unclear, but may include physical and social aspects of the work environment and structural aspects of work, such as the number of hours worked per week.

\footnotetext{
* Correspondence: escoto@umn.edu

'University of Minnesota, Department of Psychiatry, 606 24th Avenue South, \#602, Minneapolis, MN 55454, USA

Full list of author information is available at the end of the article
}

Given the potentially significant impact of work on obesity, understanding the nature of this relationship could inform the development of effective prevention and treatment interventions.

Previous research has shown inconsistent associations between the number of hours worked per week and weight, dietary intake, food habits, and physical activity, with associations often differing by gender. Much of the literature suggests that longer work hours are associated with higher Body Mass Index (BMI) [4-8], poorer dietary habits [9-12] and reduced leisure time physical activity [13-16], with associations occurring often among men and not women $[5-7,13]$. However not all research supports these findings; several studies report no association between hours worked per week and weight, food choice, or physical activity [3,7,17-19] or report associations only among women $[8,9]$. More research is
C Biomed Central 
needed to clarify the relationship between work hours, weight, and weight-related behaviors $[11,20]$ and the potential gender differences in these associations [21]. In addition, few studies have examined these relationships within single occupational groups, which may be important in understanding work-related factors that impact weight in occupations with high obesity prevalence. Further, understanding the importance of workrelated factors, such as work hours, may assist in the design of worksite interventions and policies addressing obesity $[1,22]$.

The purpose of the current study was to examine associations between work hours, food intake, physical activity and perception of ability to eat healthy at work in a sample of transit workers, composed primarily of bus operators. In a study of major U.S. occupational groups, individuals employed as motor vehicle operators (which includes bus drivers) had the highest prevalence of obesity, with estimates at $31.7 \%$ for men and $31.0 \%$ for women [1]. In addition to high rates of obesity, transit workers suffer from stressful conditions of work. Along with being a largely sedentary job $[23,24]$, structural characteristics such as shift patterns and work hours poses challenges for consistent engagement in healthy weight management behaviors [25]. Long and irregular hours are common, creating difficulties for family meals [23], constraining time available for meal preparation and exercise [22], and potentially limiting access to healthy foods [26]. While previous research has examined associations between long work hours and outcomes such as back and neck pain [27], occupational fatigue $[28,29]$, and psychological health [30] in transportation workers little to no research has examined associations with weight and weight-related behaviors in this occupational group. The present study examined associations between work hours and behavioral variables and among men and women as prior research has identified gender differences between work hours, health behaviors and obesity $[7,9,31]$. It was hypothesized that that work hours would be associated positively with BMI, poorer dietary habits, lower physical activity, and greater perceived difficulty of eating healthy at work.

\section{Methods}

\section{Sample and procedures}

Data for this study were collected as part of a worksite environmental obesity prevention intervention among Metro Transit workers (the Route H study). Details of the study design are published elsewhere [32,33]. The study was a group-randomized trial conducted with four transit garages. Interventions components targeted the garage food and physical activity environment and included increasing availability of healthy foods at the worksite, improvements in the fitness facilities and increasing the availability of group-based programs to promote healthful eating and physical activity behaviors. Measurements were collected at baseline and after the 18 -month intervention ended. Baseline measurements only were analyzed for the present study.

All employees at the four garages were invited to complete survey instruments and have height and weight measured by research staff. The average individual participation rate across the garages was $78 \%(69 \%$ to $84 \%$ ). The sample for the present study was comprised of 1086 workers (854 men; 232 women) who completed the baseline survey and answered the work hours question. Participants received a \$20 incentive for completing the survey and height and weight measurements.

This study was approved by the University of Minnesota Institutional Research Board Human Subjects Protection Program.

\section{Measures \\ Work Hours}

Work hours were measured using a single item that queried the number of hours worked at Metro Transit per week on average. Response options were $0-10$ hours; >10 - 19 hours; 20 - 29 hours; 30 - 39 hours; 40 49 hours; or $\geq 50$ hours per week. For analysis purposes, categories were collapsed into $<40$ hours, $40-49$ hours, and $\geq 50$ hours per week.

\section{Body Mass Index (BMI)}

Body weight was measured in street clothing using an electronic, calibrated scale by trained research staff. Height was measured using a portable stadiometer. Two separate measurements were taken and the average of the two values were used to calculate BMI for analysis purposes. BMI was calculated as weight $(\mathrm{kg}) /$ height $\left(\mathrm{m}^{2}\right)$.

\section{Food Intake}

Food intake was measured using a self-report food frequency questionnaire. The food frequency instrument measured a subset of foods targeted by the intervention and was adapted from two existing instruments with established validity [34]. Participants reported weekly frequency and serving size of foods consumed in the past month. For the current study, intake of fruits and vegetables (4 items), sweets (6 items), salty snacks (4 items) and sugar sweetened beverages (SSB; 2 items) was examined. Fruits and vegetable items were 100\% juice, fruit, lettuce salad, and other vegetables (all raw and cooked). Sweet foods consisted of food items such as ice cream, cookies, doughnuts, sweet muffins and chocolate candy. Salty snacks were food items such as chips, popcorn, and french fries; SSB were defined as fruit drinks and soft drinks (regular, non-diet). Summary scores for food categories (e.g., sweets) were calculated 
by multiplying the frequency of consumption of each food item (e.g., chocolate candy) per week by the usual portion size, dividing by seven to yield portion size per day and summing across items. One item queried frequency of consuming breakfast, lunch, or dinner at fast food places (e.g., McDonald's, Kentucky Fried Chicken) over the past month. Response options were never, 1-3 times last month, 1-2 times per week, 3-4 times per week, 5-6 times per week, and $\geq 7$ times per week. For analysis purposes, responses were categorized as no fast food restaurant use, or $\geq 1$-3 times per month.

As vending machines were the only source of food that could be purchased onsite at the garages [35], we assessed frequency of access to the four types of vending machines available: snack, cold food, hot beverage, and cold beverage. The vending machines consisted primarily of food items that were considered less healthful. Across the study garages, between $21 \%$ and $37 \%$ of the vending items met healthful criteria of being low calorie (i.e., $\leq 400 \mathrm{kcals}$ for entrees; $\leq 150 \mathrm{kcals}$ for snacks and sweets; $\leq 50 \mathrm{kcals}$ for cold beverages; $\leq 120 \mathrm{kcals}$ for milk), low sugar (i.e., $\leq 35 \%$ by weight for entrees, snacks, sweets; nuts, seeds, mints, and gum were sugarfree), and lowfat (i.e., $\leq 30 \%$ total kcals for snacks, entrees, sweets, cold beverages) and most items were high calorie [36]. Frequency was assessed during the past month, with response options being never, 1-3 times last month, 1-2 times per week, 3-4 times per week, 5-6 times per week, and $\geq 7$ times per week. For analysis purposes, responses were categorized as $\geq 3-4$ times/week vs. 1-2 times/week or less for snack, hot and cold beverage machines, and $\geq 2-3$ times/month vs. 1 time/month or less for cold food machines.

\section{Physical Activity}

A self-report measure was used to assess leisure time physical activity (LTPA) [37,38]. Participants reported the number of times per week they engaged in strenuous, moderate, and mild leisure time activity for more than 10 minutes. Additionally, participants reported their frequency of sweat-inducing exercise episodes during a 7-day period (never, sometimes, often). The number of moderate and strenuous episodes were combined and dichotomized into $\geq 3$ times per week vs. $<3$ times per week. The number of mild episodes was also dichotomized into $\geq 3$ times per week vs. $<3$ times per week. Finally, sweat-inducing exercise was dichotomized into sometimes/often vs. never.

\section{Perceived worksite environment related to healthful food choices}

Two single-item measures assessed perception of ease of eating healthy at work. Items were "At my workplace it is easy to eat a healthy diet" and "It's hard for me to get fruits and vegetables when I'm at work". The response scale was a five-point Likert scale ranging from strongly agree to strongly disagree. For analysis purposes, the items were recoded to a dichotomous response: agree or strongly agree vs. neutral, disagree, or strongly disagree (hard to get fruits and vegetables) and disagree or disagree strongly vs. neutral, agree, or strongly agree (easy to eat a healthy diet).

\section{Demographics}

Demographic variables were self-reported and included age, gender, race (coded white vs. other), education (coded high school or less, some college, college degree or higher), marital status (coded married or partnered vs. not), annual household income (coded as $\geq \$ 50001$ vs. $<\$ 50001)$, years worked at Metro Transit (coded as up to 5 years, $>5-15$ years, $>15$ years), and job position (coded as bus operator vs. other). Smoking status was measured using three questions. Current smokers were those who reported having smoked at least 100 cigarettes in their lifetime and had smoked a cigarette in the past seven days.

\section{Statistical analysis}

Analyses were conducted using SPSS Version 16.0 (SPSS for Windows, Rel. 16.0.1. 2007. Chicago: SPSS, Inc). Frequencies and means were calculated for each variable in the full sample. With the exception of age and BMI, all variables were coded as categorical due to their nonnormal distributions. Chi-square analyses were conducted to examine bivariate associations between hours worked per week and the categorical sociodemographic variables. Comparisons of age differences by work hour category were examined using one-way ANOVA. Multivariate logistic regression analyses were conducted in the full sample and gender-stratified to examine associations between work hours and the dichotomized behavioral variables. Multivariate linear regression analyses were conducted to examine associations between work hours and BMI, the only continuous dependent variable. Models were first examined with adjustment for basic demographic variables age, gender, and race (Model 1). Then a second model was examined with full adjustment for sociodemographic and other work-related variables (job position, education, income, race, marital status, and tenure at Metro Transit). Control variables were selected because they were associated with hours worked per week in bivariate analyses (years worked at Metro Transit, job position) or have shown associations with weight status or behavioral variables in the literature [39-41].

Models were examined to determine if the overall work hour variable was statistically significant and pvalues are presented for both Model 1 (base model) and Model 2 (fully adjusted model). Crude prevalence of transit workers reporting endorsement of the behavioral outcome variables are presented, with asterisks denoting 
significant differences $(\mathrm{p}<0.05)$ in work hour categories from the reference category $(<40$ hours per week) in the fully adjusted models. Due to the small number of women reporting use of snack and cold food vending machines in the 50 or more hour per week category, this category was combined with the 40-49 hours category for those analyses.

\section{Results}

\section{Demographics, Work, and Eating and Physical Activity Behavior Variables}

Demographic variables, by hours worked per week, are presented in Table 1. Most of the sample (72\%) worked 40 - 49 hours per week. The sample was primarily male and nearly two-thirds were white. About half the sample had completed at least some college and just over half (58\%) had an annual household income $\$ 50,001$ /year or greater. Thirty-eight percent of the sample had worked at Metro Transit between five and 15 years. Nearly three-quarters of the sample were bus operators. With the exception of age and smoking status, significant differences by work hour category were observed for all other sociodemographic and work-related variables. Of note, high percentages of women and non-whites worked less than 40 hours per week, as well as those working at Metro Transit less than five years.

Obesity prevalence was high in the full sample, over half were classified as obese $\left(B M I \geq 30 \mathrm{~kg} / \mathrm{m}^{2}\right)$ and average BMI was $32.3 \mathrm{~kg} / \mathrm{m}^{2}$ (Table 2). Over half of the sample reported eating a half serving or more of sweets per day, while less than half reported consuming that serving size of salty snacks (40\%) and sugar sweetened beverages (SSB) (38\%). Less than half $(44 \%)$ of the sample consumed 2 or more servings of fruits and vegetables per day. Frequency of fast food consumption was modest; $77 \%$ of Metro transit workers reported eating at a fast food restaurant $1-3$ times or more in the past month. Approximately one third of Metro Transit workers reported using work vending machines 3 or more times per week. Self-reported leisure-time physical activity was fairly high, over half of the transit workers reported engaging in mild or moderate/strenuous exercise 3 or more times per week and 75\% reported engaging in physical activity long enough to work up a sweat sometimes/often in a 7 -day period. Nearly $65 \%$ of the sample found it difficult to eat healthy at work and just over half agreed it was difficult to get fruits and vegetables at work.

Table 1 Demographic characteristics and health behaviors of transit workers by hours worked per week $(n=1086)$

\begin{tabular}{|c|c|c|c|c|c|}
\hline & \multicolumn{5}{|c|}{ Hours worked per week } \\
\hline & Total & $\leq 40$ & $40-49$ & $\geq 50$ & $p^{1}$ \\
\hline N (\%) & 1086 & $221(20.3)$ & $785(72.3)$ & $80(7.4)$ & \\
\hline Age (SD) & $47.7(10.2)$ & $46.3(12.2)$ & $47.9(9.6)$ & $49(9.3)$ & .102 \\
\hline Gender (\%) & & & & & .002 \\
\hline -Male & 78.6 & 70.1 & 80.6 & 82.5 & \\
\hline -Female & 21.4 & 29.9 & 19.4 & 17.5 & \\
\hline Race (\%) & & & & & $<.001$ \\
\hline -White & 62.7 & 52.9 & 66.4 & 53.8 & \\
\hline -Other & 37.3 & 47.1 & 33.6 & 46.2 & \\
\hline Education (\%) & & & & & .015 \\
\hline -High school/vocational & 49.0 & 41.1 & 51.4 & 47.5 & \\
\hline -Some college & 37.5 & 42.9 & 36.6 & 31.2 & \\
\hline -College or higher & 13.5 & 16 & 12 & 21.2 & \\
\hline Marital status (\% married or partnered) & 60.0 & 52.7 & 61.8 & 62.5 & .048 \\
\hline Income (\%) & & & & & $<.001$ \\
\hline -Less than $\$ 50001 / \mathrm{yr}$ & 42.4 & 58.6 & 39.6 & 26.2 & \\
\hline$-\$ 50001$ or greater/yr & 57.6 & 41.4 & 60.4 & 73.8 & \\
\hline Years worked at Metro Transit (\%) & & & & & $<.001$ \\
\hline -Up to 5 years & 31.5 & 56.1 & 25.8 & 18.8 & \\
\hline$\rightarrow 5-15$ years & 38.0 & 28.5 & 40.8 & 37.5 & \\
\hline ->15 years & 30.5 & 15.4 & 33.4 & 43.8 & \\
\hline Position (\%) & & & & & $<.001$ \\
\hline -Bus operator & 72.9 & 95.5 & 65.3 & 86.2 & \\
\hline -Other & 27.1 & 4.5 & 34.7 & 13.8 & \\
\hline Current smoker (\%) & 25.4 & 24.5 & 25.8 & 24.7 & .664 \\
\hline
\end{tabular}

${ }^{1} \mathrm{P}$ values from chi-square tests except for all variables except age (comparison of means using one-way ANOVA test) 
Table 2 Crude prevalence and multivariate associations: BMI, food intake, physical activity, and perception of healthy eating at work by hours worked per week in transit workers

\begin{tabular}{|c|c|c|c|c|c|c|}
\hline & \multicolumn{4}{|c|}{ Hours worked per week } & \multicolumn{2}{|c|}{ Models, $p^{1}$} \\
\hline & & & & & 1 & $\underline{2}$ \\
\hline & $\underline{\text { Total }}$ & $\leq 40(\mathrm{ref})^{2}$ & $\underline{40-49}$ & $\geq 50$ & $\bar{p}$ & $\bar{p}$ \\
\hline N & & 221 & 785 & 80 & & \\
\hline BMI $\left(\mathrm{kg} / \mathrm{m}^{2}\right)^{3}(\mathrm{SD})$ & $32.3(7.3)$ & $32.2(8.5)$ & $32.2(6.8)$ & $34.4(8.9)^{*}$ & & \\
\hline \multicolumn{7}{|l|}{ Food Frequency } \\
\hline \multicolumn{7}{|l|}{ Past month, $\geq 0.5$ servings/day, $\%$} \\
\hline -Sweets & 56.4 & 52.0 & 57.2 & 60.0 & .57 & .47 \\
\hline -Salty snacks & 40.1 & 33.5 & 41.3 & 47.5 & .04 & .08 \\
\hline$-S S B$ & 38.1 & 37.6 & 37.7 & 43.8 & .49 & .23 \\
\hline \multicolumn{7}{|l|}{ Past month, $\geq 2$ servings/day, $\%$} \\
\hline -Fruits and Vegetables & 43.8 & 43.4 & 43.7 & 46.2 & .97 & .87 \\
\hline \multicolumn{7}{|l|}{ Past month, $\geq 1-3$ times/month, $\%$} \\
\hline -Fast food & 77.1 & 77.3 & 77.5 & 72.5 & .74 & .81 \\
\hline \multicolumn{7}{|l|}{ Past month use of vending machines, $\geq 3-4$ times/week, $\%$} \\
\hline -Cold Beverage & 33.7 & 26.3 & $34.8^{*}$ & $43.0^{*}$ & .005 & .01 \\
\hline -Hot Beverage & 31.7 & 27.4 & 31.7 & 43.0 & .12 & .07 \\
\hline -Snack & 31.5 & 25.1 & 32.0 & $43.8^{*}$ & .01 & .009 \\
\hline \multicolumn{7}{|l|}{ Past month use of vending machines, $\geq 2-3$ times $/ \mathrm{mo}, \%$} \\
\hline -Cold Food & 29.5 & 24.1 & $29.9^{*}$ & $40.0^{*}$ & .02 & .004 \\
\hline \multicolumn{7}{|l|}{ Physical Activity } \\
\hline Moderate/Strenuous LTPA (\% reporting $\geq 3$ times/wk) & 57.8 & 58.5 & 57.6 & 57.7 & .79 & .66 \\
\hline Mild LTPA (\% reporting $\geq 3$ times/wk) & 50.2 & 45.5 & 51.9 & 46.2 & .39 & .65 \\
\hline Sweat Frequency (\% reporting sometimes/often within past 7 days) & 75.5 & 75.1 & 75.3 & 78.5 & .80 & .70 \\
\hline \multicolumn{7}{|l|}{ Perception of Work Environment } \\
\hline Easy to eat healthy at work (\%Disagree/strongly) & 64.7 & 62.3 & 65.7 & 62.5 & .49 & .19 \\
\hline Hard to get F\&V at work (\%Agree/strongly) & 52.2 & 49.5 & 52.8 & 54.4 & .66 & .19 \\
\hline
\end{tabular}

Model 1 is adjusted for gender, age and race

Model 2 is adjusted for gender, age, race, education, job position, years worked at MT, and marital status.

${ }^{1} \mathrm{p}$-values represent significance of the overall work hour variable from multivariate logistic regression analyses $(\mathrm{df}=2)$

${ }^{2}$ Reference category is $<40$ hours per week

${ }^{3}$ Multiple linear regression analysis with work hours coded as dummy variables $(<40$ v. $40-49 ;<40$ v. $\geq 50)$

*Denotes significant differences $(p<0.05)$ in prevalence from reference category $(<40$ hours per week) in fully adjusted model (Model 2$)$

\section{Work Hours, Food Intake and Perceived Work Environment}

Table 2 presents average BMI and crude prevalence of transit workers reporting frequency of food intake, physical activity, and perceptions of the work environment by work hour categories in the full sample. Associations existed between the number of hours worked per week and BMI, frequency of use of cold beverage, snack vending, and cold food vending machines; p-values are presented for the fully adjusted models only. BMI was highest among those who worked 50 or more hours per week and was significantly higher than those working less than 40 hours per week (34.4 v. $32.2 \mathrm{~kg} / \mathrm{m}^{2}, \mathrm{p}=$ 0.03). Compared to transit workers working less than 40 hours per week, those working 50 or more hours per week made more frequent purchases from vending machines: snack ( $44 \%$ v. $25 \%, \mathrm{p}=0.002)$, cold beverage (43\% v. $26 \%, \mathrm{p}=0.004)$, and cold food $(40 \%$ v. $24 \%, \mathrm{p}=$ $0.001)$. Cold food (30\% v. $24 \%, \mathrm{p}=0.03$ ) and cold beverage $(35 \%$ v. $26 \%, p=0.03)$ vending machine use was more frequent among those working 40 - 49 hours per week compared to less than 40 hours per week.

Transit workers working 50 or more hours per week were more likely to have a higher intake of salty snacks ( $48 \%$ v. $34 \%, p=0.03$ in Model 1), but the overall work hour variable was not statistically significant after adjustment. None of the other food frequency variables, leisure- time physical activity, or perceived ease of eating healthy at work was associated with the number of hours worked per week. 


\section{Gender differences in work hours, food intake and perceived work environment}

Generally, BMI, food intake, and perceptions of the work environment differed by gender. Average BMI was higher among females than males $\left(33.4 \mathrm{~kg} / \mathrm{m}^{2} \mathrm{v} .32 .1\right.$ $\left.\mathrm{kg} / \mathrm{m}^{2}, \mathrm{p}=0.03\right)$. Compared with men, women reported higher intake of fruits and vegetables $(53 \%$ v. $41 \%$, $\mathrm{p}=0.001)$ and less frequent use of cold food $(21 \% \mathrm{v}$. $32 \%, \mathrm{p}=0.001)$ and hot beverage vending machines $(24 \%$ v. $34 \%, \mathrm{p}=0.004)$.

Table 3 presents average BMI and crude prevalence of transit workers reporting frequency of food intake and perceptions of the work environment by work hour categories, stratified by gender. Results among males were analogous to the results in the full sample. Average BMI was highest among those who worked 50 or more hours per week and remained significantly higher than those working less than 40 hours per week $\left(34.3 \mathrm{~kg} / \mathrm{m}^{2}\right.$ v. $\left.31.4 \mathrm{~kg} / \mathrm{m}^{2}, \mathrm{p}=0.02\right)$ after full adjustment. Compared to working less than 40 hours per week, men working 50 or more hours per week more frequently used cold beverage $(48 \%$ v. $26 \%, \mathrm{p}=0.001)$ and cold food $(47 \%$ v. $28 \%, \mathrm{p}<0.001)$ vending machines. Further, males working $40-49$ hours $(33 \%$ v. $22 \%, p=0.04)$ and 50 or more hours $(52 \%$ v. $22 \%, \mathrm{p}<0.001)$ per week used snack vending machines more frequently. Similar to the

Table 3 Crude prevalence and multivariate associations: BMI, food intake, physical activity, and perception of healthy eating at work by hours worked per week stratified by gender

\begin{tabular}{|c|c|c|c|c|c|c|c|c|c|c|}
\hline & \multicolumn{10}{|c|}{ Hours worked per week } \\
\hline & \multicolumn{3}{|c|}{ Males } & \multicolumn{2}{|c|}{ Models, $p^{1}$} & \multicolumn{2}{|c|}{ Females } & & \multicolumn{2}{|c|}{ Models, $p^{1}$} \\
\hline & $\leq 40{\text { (ref })^{2}}^{2}$ & $\underline{40-49}$ & $\geq 50$ & 1 & $\underline{2}$ & $\leq 40$ (ref) $^{2}$ & $\underline{40-49}$ & $\underline{\geq 50}$ & 1 & $\underline{2}$ \\
\hline $\mathrm{n}$ & 155 & 633 & 66 & & & 66 & 152 & 14 & & \\
\hline BMI $\left(\mathrm{kg} / \mathrm{m}^{2}\right)^{3}(\mathrm{SD})$ & $31.4(7.5)$ & $32(6.8$ & $34.3(9.1)^{*}$ & & & $34.1(10.2)$ & $32.9(6.8)$ & $34.9(7.9)$ & & \\
\hline \multicolumn{11}{|l|}{ Food Frequency } \\
\hline \multicolumn{11}{|l|}{ Past month, $\geq 0.5$ servings/day, \% } \\
\hline -Sweets & 50.3 & 57.5 & 59.1 & .56 & .75 & 56.1 & 55.9 & 64.3 & .79 & .66 \\
\hline -Salty snacks & 27.7 & 42.7 & 45.5 & .005 & .08 & 47.0 & 35.5 & 57.1 & .18 & .28 \\
\hline$-S S B$ & 36.1 & 39.5 & 39.3 & .28 & .25 & 40.9 & 30.3 & 35.7 & .35 & .45 \\
\hline \multicolumn{11}{|l|}{ Past month, $\geq 2$ servings/day, $\%$} \\
\hline Fruits and Vegetables & 38.1 & 42.5 & 37.9 & .28 & .36 & 56.1 & 48.7 & $85.7^{*}$ & .02 & .04 \\
\hline \multicolumn{11}{|l|}{ Past month, $\geq 1-3$ time, $\%$} \\
\hline Fast food & 73.4 & 77.5 & 72.7 & .57 & .66 & 86.7 & 77.6 & 71.4 & .36 & .25 \\
\hline \multicolumn{11}{|c|}{ Past month, use of vending machines, $\geq 3-4$ times/wk, $\%$} \\
\hline -Cold Beverage & 25.8 & 34.7 & $47.7^{*}$ & .005 & .004 & 27.4 & 35.1 & 21.4 & .11 & .11 \\
\hline -Hot Beverage & 28.0 & 34.0 & 46.2 & .08 & .06 & 25.8 & 22.1 & 28.6 & .56 & .39 \\
\hline- Snack ${ }^{4}$ & 21.9 & $33.2^{*}$ & $51.5^{*}$ & $<0.001$ & $<0.001$ & 32.8 & & 5.5 & .51 & .50 \\
\hline \multicolumn{11}{|c|}{ Past month, use of vending machines, $\geq 2-3$ times/mo, $\%$} \\
\hline -Cold Food ${ }^{4}$ & 28.0 & 31.3 & $47.0^{*}$ & .01 & .001 & 14.5 & & $8^{*}$ & .07 & .04 \\
\hline \multicolumn{11}{|l|}{ Physical Activity } \\
\hline \multicolumn{11}{|l|}{ Reporting LTPA $\geq 3$ times/wk, \% } \\
\hline -Mod/Strenuous & 60.9 & 60.5 & 63.1 & .96 & .96 & 52.5 & 44.8 & 30.8 & .29 & .25 \\
\hline -Mild & 47.7 & 53.6 & 50.8 & .46 & .88 & 40.3 & 44.9 & 23.1 & .48 & .45 \\
\hline \multicolumn{11}{|l|}{ Sweat Frequency within the past 7 days, $\%$} \\
\hline -Sometimes/often & 76.0 & 76.5 & 83.3 & .42 & .39 & 73.0 & 70.3 & 53.8 & .36 & .23 \\
\hline \multicolumn{11}{|l|}{ Perception of Work Environment } \\
\hline Easy to eat healthy at work (\% Disagree/strongly) & 60.4 & 65.0 & 60.6 & .37 & .21 & 66.7 & 68.5 & 71.4 & .93 & .81 \\
\hline Hard to get F\&V at work (\%Agree/strongly) & 49.0 & 51.3 & 52.3 & .66 & .19 & 50.8 & 58.9 & 64.3 & 68 & .68 \\
\hline
\end{tabular}

Model 1 is adjusted for age and race

Model 2 is adjusted for age, race, education, job position, years worked at MT, and marital status.

${ }^{1} \mathrm{p}$-values represent significance of the overall work hour variable from multivariate logistic regression analyses $(\mathrm{df}=2)$

${ }^{2}$ Reference category is $<40$ hours per week

${ }^{3}$ Multiple linear regression analysis with work hours coded as dummy variables ( $<40$ v. $40-49 ;<40$ v. $\geq 50$ )

${ }^{4}$ Reference category is $<40$ hours per week; 40 - 49 and $\geq 50$ hours per week category combined due to small number of women working $\geq 50$ hours per week endorsing snack and cold food vending machine use

*Denotes significant differences $(p<0.05)$ in prevalence from reference category $(<40$ hours per week) in fully adjusted model (Model 2 ) 
full sample, salty snack intake was highest in the 50 or more hours per week category, but the work hour variable was not significant in the fully adjusted model. No other food frequency or physical activity variables were associated with number of hours worked per week. With the exception of fruit and vegetable intake and cold food vending machine use, associations were not found between work hours and BMI, food frequency, or physical activity variables among females. Fruit and vegetable intake was highest among females working 50 or more hours per week ( $86 \%$ v. $56 \%, \mathrm{p}=0.04)$ compared to those working less than 40 hours per week. When analyzing fruits and vegetable items individually (i.e., fruit juice, fruit, lettuce salad, other vegetables) consumption of 'fruit' and 'lettuce salad' showed significant associations with number of hours worked per week (data not shown). Frequency of use of cold food vending machines was higher among women working 40 or more hours per week $(23 \%$ v. $15 \%, \mathrm{p}=0.04)$ compared to those working less than 40 hours per week.

\section{Discussion}

The findings of this study showed that long work hours were associated with high BMI and less healthful food habits in male transit workers; to a lesser extent, both healthful and less healthful food habits were associated with long work hours in female transit workers. Males working 50 or more hours per week had higher BMI and reported greater use of cold beverage, snack, and cold food vending machines than those working less than 40 hours per week. These associations were present after adjustment for both sociodemographic and workrelated factors that are likely to account for differences in food habits, such as age, race, education, income and job position. In contrast, the number of hours worked per week was not associated with BMI and showed very few associations with food habits among female transit workers. Women working at least 40 hours per week more frequently used cold food vending machines. Surprisingly, those working 50 or more hours per week were most likely to consume 2 or more daily servings of fruits and vegetables. These results may indicate that the length of the working day may increase reliance on foods that are available at workplace facilities, particularly among male transit workers.

Aspects of the current study findings are consistent with prior research. As in other studies, obesity prevalence was high in this group of transit workers $[1,42,43]$ and we identified associations between work hours and BMI among men only [5-7]. Further, work hours were associated with eating behavior between men and women differently $[9,10]$. In the present study, men working longer hours were more heavily dependent than were women on convenience foods purchased from the garage vending machines. Previous research indicates that men are more likely than women to purchase lunch at work and are more likely to report convenience as influencing food choice for lunch [44]. The gender difference in the association between work hours and vending machine use may be due to job position of the transit workers. A higher percentage of females were bus operators ( $85 \%$ vs. $70 \%, p<0.001)$, thus may have had limited exposure to garage vending machines as their time at the worksite may be brief. Longer work hours, particularly for roles that might require more time at the garage (i.e., bus maintenance, management) may create opportunity for frequent use of onsite food sources. Female transit workers generally used vending machines less frequently than males (i.e., cold food, hot beverage).

Contrary to our expectations, female transit workers who worked 50 or more hours per were more likely to consume 2 or more servings of fruit and vegetables per day compared to those working less than 40 hours per week. The reasons for this association are not clear. Poorer dietary intake has been associated with longer work hours among women [9] and sociodemographic variables which may have helped explain the association (e.g., education, income, marital status) [45-48] did not vary significantly across work hour categories among females in our sample. Income was the only sociodemographic variable that was significantly associated with fruit and vegetable consumption; women having a household income of $\$ 50001$ or more were more likely to report consuming 2 or more servings of fruits and vegetables per day (data not shown). The association between work hours and fruit and vegetable consumption may be due to obesity prevalence in females working 50 or more hours per week. This group of transit workers had the highest average BMI $\left(34.9 \mathrm{~kg} / \mathrm{m}^{2}\right)$ in the sample, thus are likely to be attempting to lose weight [49]. Such individuals (i.e., overweight, obese) have been found to report higher consumption of fruits and vegetables [50] perhaps accounting for the prevalence in this work hour category. Finally, our finding may be due to the small number of women in this highest work hour category ( $\geq 50$ hours per week). While $86 \%$ of women reported consuming 2 or more daily servings of fruits and vegetables, this represented 12 of 14 women. Hence, our findings need replication with a larger sample of female transit workers.

While the current study results indicate that transit workers who work long hours more frequently purchase foods from vending machines, other measures of poor eating behavior were not associated with hours worked, such as consuming fast foods, sweet foods, and sugar sweetened beverages. Further, work hours were not associated with reported leisure-time physical activity, 
which differs from the results of previous studies [14-16,51]. Although the relationship between hours worked per week and exercise has not been established consistently [18], bus operators report that more leisure time exercise and shortening the length of work days as among the most important ways to improve their health and work environment [52]. Additional research is needed to clarify the specific weight-related behaviors that are most disrupted by long work hours in transit workers. Future studies should examine variables such as meal frequency and meal timing, which have been associated with overweight and obesity [53]. As BMI was significantly higher among women than men, and over $60 \%$ of female transit workers were obese, further work should also focus on weight management in this population.

The findings of this study have implications for worksite intervention design and policy. Our results underscore the importance of worksite food environments containing healthy food choices that are readily accessible. In the Route H study, none of the garages had cafeterias onsite and only one garage had restaurants in the immediate area [36]. Thus vending machines were largely the only source of food available [35]. Transit workers who worked longer hours may have used vending machines regularly due to lack of other alternatives and/ or time, given bus operators do not get scheduled meal breaks. Prior research suggests that workers frequently consume food from worksite facilities and that food offerings at the worksite are related to diet quality [54]. The limited food environment coupled with long working hours may be important contributing factors in the development and maintenance of obesity. Finally, in order to inform policy interventions, more research is needed to explore strategies such as flexible work arrangements and expanding driver control over work scheduling $[23,55]$, given that our data suggests that long work hours carry consequences for weight and weight-related behavior in this occupational group.

The present study had several strengths and limitations. Strengths include a large mixed-gender sample of transit workers and several measures of dietary intake, eating behavior, and leisure time physical activity. This study is limited in its use of a cross-sectional design; no inferences can be made regarding causality. Additionally, our primary measures of dietary intake and physical activity were self-report, which may have been inaccurately reported [56,57]. The small sample of women may have limited our power in testing the gender-stratified associations. Only $6 \%$ of female transit workers were in the highest work hour category, potentially providing insufficient power to detect associations. Lower number of women working overtime has been found in other studies [58]. The current study's sample consisted primarily of bus operators (72\%), but included small numbers of management and bus maintenance staff. Thus results reflect associations for transit workers across job positions, thus may not reflect the experience of solely bus operators. Our research contains a single work-related factor, the number of hours worked per week. Future research should expand measurement of work-related factors by including variables such as work shift, job stress, and job flexibility, which may be associated with health related behavior [22]. Finally, obesity prevalence was high in this sample, $56 \%$ of the transit workers were considered obese (BMI $\geq 30 \mathrm{~kg} / \mathrm{m}^{2}$ ). Although high obesity prevalence is to be expected in a sample of transportation workers [1], this high prevalence may impact dietary and physical activity behaviors $[49,50]$. As the survey response rate was high in this study (78\%), results may generalize well to transportation workers, but may have limited generalizability outside this occupational group.

\section{Conclusion}

Longer work hours were associated with BMI, fruit and vegetable intake, and frequent use of garage vending machines in a sample of Metro Transit workers. Males who worked the longest hours (50 or more hours per week) had the highest BMI and were the most frequent users of vending machines at garage worksites. Longer work hours were associated with increased fruit and vegetable intake among women as well as more frequent use of cold food vending machines. Long work hours may increase dependence upon food availability at the worksite among transit workers, underscoring the importance of providing healthy food choices at the transit garages.

\section{Acknowledgements}

This research was funded with a grant from the National Institutes of Health $\mathrm{NIH}$ R01 HL 079478. Additional support for the current study was provided by the Regional Postdoctoral Training Grant In Eating Disorders Research (NIH 5T32MH082761-02).

\section{Author details}

'University of Minnesota, Department of Psychiatry, 606 24th Avenue South, $\# 602$, Minneapolis, MN 55454, USA. ${ }^{2}$ University of Minnesota, Division of Epidemiology \& Community Health, Suite 300 WBOB, 1300 South Second Street, Minneapolis, MN 55454, USA.

\section{Authors' contributions}

SAF, LJF, TT and PJH contributed to the design of the study. KHE formulated the research question, conducted data analysis, and wrote the manuscript. $\mathrm{PJH}$ provided guidance with the statistical analysis of the data. All authors assisted with revising the manuscript. All authors read and approved the final manuscript.

\section{Competing interests}

The authors declare that they have no competing interests.

Received: 6 July 2010 Accepted: 20 December 2010 Published: 20 December 2010 


\section{References}

1. Caban AJ, Lee DJ, Fleming LE, Gomez-Marin O, LeBlanc W, Pitman T: Obesity in US workers: The National Health Interview Survey, 1986 to 2002. Am J Public Health 2005, 95(9):1614-1622.

2. Sparks K, Cooper C, Fried Y, Shirom A: The effects of hours of work on health: A meta-analytic review. J Occup Organ Psychol 1997, 70(4):391-408.

3. Maruyama S, Morimoto K: Effects of long workhours on life-style, stress and quality of life among intermediate Japanese managers. Scand J Work Environ Health 1996, 22(5):353-359.

4. Lallukka T, Laaksonen M, Martikainen P, Sarlio-Lähteenkorva S, Lahelma E: Psychosocial working conditions and weight gain among employees. Int J Obes 2005, 29(8):909-915.

5. Ko GT, Chan JC, Chan AW, Wong PT, Hui SS, Tong SD, Ng SM, Chow F, Chan $\mathrm{CL}$ : Association between sleeping hours, working hours and obesity in Hong Kong Chinese: the 'better health for better Hong Kong' health promotion campaign. Int J Obes 2007, 31(2):254-260.

6. Ostry AS, Radi S, Louie AM, LaMontagne AD: Psychosocial and other working conditions in relation to body mass index in a representative sample of Australian workers. BMC Public Health 2006, 6:53.

7. Shields M: Long working hours and health. Health Rep 1999, 11:33-48.

8. Lallukka T, Lahelma E, Rahkonen O, Roos E, Laaksonen E, Martikainen P, Head J, Brunner E, Mosdol A, Marmot M, Sekine M, Nasermoaddeli A, Kagamimori S: Associations of job strain and working overtime with adverse health behaviors and obesity: evidence from the Whitehall II Study, Helsinki Health Study, and the Japanese Civil Servants Study. SoC Sci Med 2008, 66(8):1681-1698.

9. Jones F, O'Connor DB, Conner M, McMillan B, Ferguson E: Impact of daily mood, work hours, and iso-strain variables on self-reported health behaviors. J Appl Psychol 2007, 92(6):1731-1740.

10. Wardle J, Steptoe A, Oliver G, Lipsey Z: Stress, dietary restraint and food intake. J Psychosom Res 2000, 48(2):195-202.

11. Devine CM, Farrell TJ, Blake CE, Jastran M, Wethington E, Bisogni CA: Work conditions and the food choice coping strategies of employed parents. Nutr Educ Behav 2009, 41(5):365-370.

12. Nakamura K, Shimai S, Kikuchi S, Takahashi H, Tanaka M, Nakano S, Motohashi Y, Nakadaira H, Yamamoto M: Increases in body mass index and waist circumference as outcomes of working overtime. Occup Med 1998, 48(3):169-173.

13. Artazcoz L, Corts I, Escrib-Agir V, Cascant L, Villegas R: Understanding the relationship of long working hours with health status and health-related behaviours. J Epidemiol Community Health 2009, 63(7):521-527.

14. Burton NW, Turrell G: Occupation, hours worked, and leisure-time physical activity. Prev Med 2000, 31(6):673-681

15. Mein G, Shipley M, Hillsdon M, Ellison GTH, Marmot M: Work, retirement and physical activity: cross-sectional analyses from the Whitehall II study. Eur J Public Health 2005, 15(3):317-322.

16. Popham F, Mitchell R: Leisure time exercise and personal circumstances in the working age population: longitudinal analysis of the British household panel survey. J Epidemiol Community Health 2006, 60(3):270-274

17. Nakanishi N, Nakamura K, Ichikawa S, Suzuki K, Tatara K: Lifestyle and the development of hypertension: a 3-year follow-up study of middle-aged Japanese male office workers. Occup Med 1999, 49(2):109-114.

18. van der Hulst M: Long workhours and health. Scand J Work Environ Health 2003, 29(3):171-188.

19. Parsons TJ, Thomas C, Power C: Estimated activity patterns in British 45 year olds: cross-sectional findings from the 1958 British birth cohort. Eur J Clin Nutr 2009, 63(8):978-985.

20. Schulte PA, Wagner GR, Downes A, Miller DB: A framework for the concurrent consideration of occupational hazards and obesity. Ann Occup Hyg 2008, 52(7):555-566.

21. Devine CM, Connors MM, Sobal J, Bisogni CA: Sandwiching it in: spillover of work onto food choices and family roles in low- and moderateincome urban households. Soc Sci Med 2003, 56(3):617-630.

22. Caruso CC: Long working hours, safety, and health: toward a National Research Agenda. Am J Ind Med 2006, 49(11):930-942.

23. Evans GW: Working on the hot seat: Urban bus operators. Accid Anal Prev 1994, 26(2):181-193.

24. Szeto GPY, Lam P: Work-related musculoskeletal disorders in urban bus drivers of Hong Kong. J Occup Rehabil 2007, 17(2):181-198.
25. Hedberg GE: Comparison between two programmes for reducing the levels of risk indicators of heart diseases among male professional drivers. Occup Environ Med 1998, 55(8):554-561.

26. Ragland DR, Krause N, Greiner BA, Fisher JM: Studies of health outcomes in transit operators: policy implications of the current scientific database. J Occup Health Psychol 1998, 3(2):172-187.

27. Krause N, Ragland DR, Greiner BA, Syme SL, Fisher JM: Psychosocial job factors associated with back and neck pain in public transit operators. Scand J Work Environ Health 1997, 23(3):179-186.

28. Biggs $\mathrm{H}$ : Fatigue factors affecting metropolitan bus drivers: A qualitative investigation. Work 2009, 32(1):5-10.

29. Machin MA, Hoare PN: The role of workload and driver coping styles in predicting bus drivers' need for recovery, positive and negative affect, and physical symptoms. Anxiety, Stress, Coping 2008, 21(4):359-375.

30. Tse JLM, Flin R, Mearns K: Facets of job effort in bus driver health: deconstructing "effort" in the effort-reward imbalance model. J Occup Health Psychol 2007, 12(1):48-62.

31. Artazcoz L, Corts I, Borrell C, Escrib-Agir V, Cascant L: Gender perspective in the analysis of the relationship between long workhours, health and health-related behavior. Scand J Work Environ Health 2007, 33(5):344-350.

32. French SA, Harnack LJ, Toomey TL, Hannan PJ: Association between body weight, physical activity and food choices among metropolitan transit workers. Int J Behav Nutr Phys Act 2007, 4:52.

33. French SA, Harnack LJ, Hannan PJ, Mitchell NR, Gerlach AF, Toomey TL: Worksite environment intervention to prevent obesity among metropolitan transit workers. Prev Med 2010, 50(4):180-185.

34. Thompson FE, Subar AF, Smith AF, Midthune D, Radimer KL, Kahle LL, Kipnis V: Fruit and vegetable assessment: performance of 2 new short instruments and a food frequency questionnaire. J Am Diet Assoc 2002, 102(12):1764-1772

35. French SA, Hannan PJ, Harnack LJ, Mitchell NR, Toomey TL, Gerlach A: Pricing and availability intervention in vending machines at four bus garages. J Occup Environ Med 2010, 52(Suppl 1):S29-33.

36. Shimotsu ST, French SA, Gerlach AF, Hannan PJ: Worksite environment physical activity and healthy food choices: measurement of the worksite food and physical activity environment at four metropolitan bus garages. Int J Behav Nutr Phys Act 2007, 4:17.

37. Godin G, Shephard RJ: A simple method to assess exercise behavior in the community. Can J App/ Sport Sci 1985, 10(3):141-146.

38. Godin G, Jobin J, Bouillon J: Assessment of leisure time exercise behavior by self-report: a concurrent validity study. Can J Public Health 1986 77(5):359-362

39. Wang $Y$, Beydoun M: The obesity epidemic in the United States-gender, age, socioeconomic, racial/ethnic, and geographic characteristics: a systematic review and meta-regression analysis. Epidemiol Rev 2007 29:6-28.

40. Block G, Rosenberger WF, Patterson BH: Calories, fat and cholesterol: intake patterns in the US population by race, sex and age. Am J Public Health 1988, 78(9):1150-1155.

41. Jeffery R, Rick A: Cross-sectional and longitudinal associations between body mass index and marriage-related factors. Obes Res 2002, 10(8):809-815.

42. Hedberg GE: Risk indicators of ischemic heart disease among male professional drivers in Sweden. Scand J Work Environ Health 1993, 19:326-333.

43. Rosengren A, Anderson $\mathrm{K}$, Wilhelmsen L: Risk of coronary heart disease in middle-aged male bus and tram drivers compared to men in other occupations: a prospective study. Int J Epidemiol 1991, 20(1):82-87.

44. Blanck HM, Yaroch AL, Atienza AA, Yi SL, Zhang J, Masse LC: Factors influencing lunchtime food choices among working Americans. Health Educ Behav 2009, 36(2):289-301.

45. Estaquio C, Druesne-Pecollo N, Latino-Martel P, Dauchet L, Hercberg S, Bertrais S: Socioeconomic differences in fruit and vegetable consumption among middle-aged French adults: adherence to the 5 A Day recommendation. J Am Diet Assoc 2008, 108(12):2021-2030.

46. Trudeau E, Kristal AR, Li S, Patterson RE: Demographic and psychosocial predictors of fruit and vegetable intakes differ: implications for dietary interventions. J Am Diet Assoc 1998, 98(12):1412-1417.

47. Thompson B, Demark-Wahnefried W, Taylor G, McClelland JW, Stables G, Havas S, Feng Z, Topor M, Heimendinger J, Reynolds KD, Cohen N: Baseline fruit and vegetable intake among adults in seven 5 a day study centers 
located in diverse geographic areas. J Am Diet Assoc 1999, 99(10):1241-1248.

48. Kamphuis CBM, Giskes K, de Bruijn G, Wendel-Vos W, Brug J, van Lenthe F: Environmental determinants of fruit and vegetable consumption among adults: a systematic review. Br J Nutr 2006, 96(4):620-635.

49. Weiss EC, Galuska DA, Khan LK, Serdula MK: Weight-control practices among U.S. adults, 2001-2002. Am J Prev Med 2006, 31(1):18-24.

50. Andreyeva T, Long M, Henderson K, Grode G: Trying to lose weight: diet strategies among Americans with overweight or obesity in 1996 and 2003. J Am Diet Assoc 2010, 110(4):535-542.

51. Bushnell PT, Colombi A, Caruso C, Tak S: Work schedules and health behavior outcomes at a large manufacturer. Ind Health 2010, 48(4):395-405.

52. Emdad R, Belkic K, Theorell T, Cizinsky S: What prevents professional drivers from following physicians' cardiologic advice? Psychother Psychosom 1998, 67(4-5):226-240.

53. Berg C, Lappas G, Wolk A, Strandhagen E, Torn K, Rosengren A, Thelle D, Lissner L: Eating patterns and portion size associated with obesity in a Swedish population. Appetite 2009, 52(1):21-26.

54. Roos E, Sarlio-Lähteenkorva S, Lallukka T: Having lunch at a staff canteen is associated with recommended food habits. Public Health Nutr 2004 7(1):53-61.

55. Evans GW: Urban bus driving: An international arena for the study of occupational health psychology. J Occup Health Psychol 1998, 3(2):99-108

56. Heitmann BL, Lissner L, Osler M: Do we eat less fat, or just report so? Int $J$ Obes 2000, 24(4):435-442.

57. Sallis JF, Saelens BE: Assessment of physical activity by self-report: status, limitations, and future directions. Res Q Exerc Sport 2000, 71(2 Suppl): S1-14.

58. Grosch JW, Caruso CC, Rosa RR, Sauter SL: Long hours of work in the U.S.: associations with demographic and organizational characteristics, psychosocial working conditions, and health. Am J Ind Med 2006, 49(11):943-952.

doi:10.1186/1479-5868-7-91

Cite this article as: Escoto et al: Work hours, weight status, and weightrelated behaviors: a study of metro transit workers. International Journal of Behavioral Nutrition and Physical Activity 2010 7:91.

\section{Submit your next manuscript to BioMed Central and take full advantage of:}

- Convenient online submission

- Thorough peer review

- No space constraints or color figure charges

- Immediate publication on acceptance

- Inclusion in PubMed, CAS, Scopus and Google Scholar

- Research which is freely available for redistribution

Submit your manuscript at www.biomedcentral.com/submit
Biomed Central 